\title{
SANParks, people and adaptive management: Understanding a diverse field of practice during changing times
}

\author{
Authors: \\ Louise K. Swemmer ${ }^{1}$ \\ Sandra Taljaard ${ }^{2}$ \\ Affiliations: \\ ${ }^{1}$ Savanna and Arid Research \\ Unit, South African National \\ Parks, Phalaborwa, \\ South Africa \\ ${ }^{2}$ People and Conservation \\ Department, South African \\ National Parks, Northern \\ Cluster, Golden Gate National \\ Park, South Africa

\section{Correspondence to:} \\ Louise Swemmer \\ Email: \\ louises@sanparks.org \\ Postal address: \\ Private Bag X402, Skukuza, \\ Kruger National Park, \\ South Africa \\ Dates: \\ Received: 04 Aug. 2010 \\ Accepted: 13 Mar. 2011 \\ Published: 13 May 2011 \\ How to cite this article: \\ Swemmer, L.K. \& Taljaard, \\ S., 2011, 'SANParks, people \\ and adaptive management: \\ Understanding a diverse field \\ of practice during changing \\ times', Koedoe 53(2), Art. \\ \#1017, 7 pages. doi:10.4102/ \\ koedoe.v53i2.1017
}

\section{(C) 2011. The Authors.} Licensee: OpenJournals Publishing. This work is licensed under the Creative Commons Attribution License.
Biodiversity conservation is often measurable and achievable and has been reasonably successful within the boundaries of national parks. However, the concept of parks providing tangible benefits and hence being seen as 'valuable' to the majority of the nation has been more difficult to define, measure and, importantly, deliver on. This function has traditionally fallen under what is currently known as the People and Conservation Department, which has a rich history in South African National Parks (SANParks) of change and adaptive learning in terms of defining core functions and associated management strategies, spanning from its original inception as the Information Services Department over 80 years ago. Learning from and in some cases, adapting to change, is evident throughout this broad scale national evolution of the department, from an initial focus on information sharing and education in the 1930s, to what we see today. This includes the primary focus areas of cultural resource management and indigenous knowledge, community relations, environmental education, awareness, youth outreach, interpretation and training.

At a more local, park scale, there is a current drive to formalise the adaptive management and learning process for the people component of protected areas through the alignment of relevant project, programme and park objectives with those at a corporate or national level. Associated with this is an attempt to further align the associated monitoring, evaluation and reporting processes, thereby completing the formal adaptive management loops in order to facilitate and stimulate co-learning within and between relevant responsible departments within the organisation.

Conservation implications: Benefit sharing through biodiversity conservation has been shown to be crucial for the long-term success of protected areas, but the practicalities of implementing this are thwart with challenges. Despite this, SANParks is attempting to facilitate and promote benefits through conservation, specifically in the sense of benefits that support livelihoods whilst reducing vulnerability. With this in mind, we acknowledge the importance of the concepts of scale, resilience, complexity and adaptive learning for, and during, this process.

\section{Introduction}

The primary focus of South African National Parks (SANParks) is the conservation of protected areas and their associated biodiversity, for the pride and benefit of the nation (see SANParks 2006). SANParks has a strong history of successful biodiversity conservation, achieved through the identification of well structured management objectives and the implementation of intensive monitoring programmes (SANParks 1997). More recently, the formal implementation of the adaptive management approach by park management and scientists, involving regular monitoring and feedback loops that inform the re-evaluation of management objectives and techniques for biodiversity conservation, has further enhanced the management effectiveness for the biodiversity component of parks at various levels (Roux \& Foxcroft 2011). However, an important component of SANParks' function is to ensure that the potential benefits of biodiversity conservation are accessible to the broader society. This ensures the delivery of the SANParks mandate, as well as constituency building for conservation. In reality, this 'people component' has received somewhat less attention and support in the past, having been previously criticised by some as not making a significant contribution towards the SANParks mission (Pollard, Shackleton \& Carruthers 2003).

Historically, the various stakeholder groups that derived benefits from protected areas were determined primarily by the management era at the time, and this has played a large role in influencing the ways in which the people components of SANParks have been managed over the years. The formal adoption of the strategic adaptive management (SAM) (Biggs \& Rogers 
2003) approach in SANParks in the early 2000s did not filter through to the people components of SANParks management until very recently and, as a result, there are currently few examples of formal adaptive management being practiced in this field within the organisation. Despite the lack of formal strategic adaptive management, the dynamic process illustrated in the longer-term development of the people component of SANParks, then known as the National Parks Board (NPB) or Nasionale Parkeraad (NPR) in Afrikaans, over the past 84 years does demonstrate a certain number of lessons learnt to date, some of which have contributed towards a degree of informal adaptation to change. In some cases this adaptation was conscious and in others not, but ultimately it was about attempting to adapt and, probably more accurately, to survive the challenging circumstances and requirements of an ever-changing environment. These adaptations were driven by changes in the national and global approach to conservation, as well as by national and international politics and changes in legislation (Pollard et al. 2003; Taljaard 2008). This paper aims to outline key events and milestones during the evolution of the people-centred approach to conservation over the last 80 years. We further aim to highlight both the positive and negative influences contributing to the adoption of formal adaptive planning and management tools.

\section{The historical evolution of the People and Conservation Department}

\section{The early days}

Although the People and Conservation Department (P\&C) currently covers a wide range of functions, including cultural resource and indigenous knowledge management, community relationship building, local economic empowerment, environmental education, outreach and awareness, interpretation and training, as well as youth outreach, it began with simpler informational and educational functions from as early as 1952, when the first formal information officer was appointed (Taljaard 2008). This official post was initiated as a response to a number of school groups and scientific expeditions that took place in the Kruger National Park (KNP) between 1932 and 1950 (Milne 1996; Taljaard 2008). As more national parks were established between the 1950s and 1980s, the need for people-interaction on an interpretational and educational level grew rapidly, resulting in the need to employ more staff in the Information Services Department.

Up to this period, the main focus on the interpretational and educational front was on White South Africans, which was in line with the political order of the day. However, in 1981, an explicit, formally documented intent to serve the broader South African public was published (NPR 1981a; NPR 1981b). This was the first of its kind and marked a watershed of change within the approach of inclusively educating all people on environmental aspects and related issues. This move was clearly linked to the political changes and instability that characterised South Africa in the 1980s. In 1987, the first mention was made of a partnership between conservation areas and their neighbours, stressing the importance of 'conservation education' (Taljaard 2008). In 1989, a report appeared titled 'Multicultural environmental education' (NPR 1989). This report focused even more directly on the inclusion of neighbouring communities in educational programmes and also noted that the KNP accommodated the first 'non-White' (standard jargon of that era, now considered an exclusionary term) groups in its bush camps during that year. There were other 'multicultural' programmes forthcoming from these efforts and it was reported that these interventions were valuable and successful attempts to encourage the development of interracial relationships between the SANParks and local communities (NPR 1989). One example of this was the five non-White schools that attended the National Environmental Youth Symposium (NYES) for the first time in 1987. The NYES was initiated by SANParks in 1981 and hosted annually in the Golden Gate National Park. The main aim of the NYES was to promote environmental awareness and appreciation by the youth and, by 1988, the number of non-White participating schools had grown to sixteen (NPR 1989).

\section{The emergence of the Social Ecology Unit}

Changes in a new democratic dispensation that picked up momentum in the early 1990s marked the first democratic elections in 1994, and this led to the establishment of the Social Ecology Unit (SE) in that same year. The main aim of the SE was to improve strained relationships with neighbouring communities, avert threats such as poaching and land grabs and respond to the general trends towards democracy in southern Africa (SANParks 2001). The midnineties also marked the start of the Integrated Conservation and Development Programmes (ICDPs) in South Africa, aimed at integrating environmental protection with poverty reduction (Campbell, Sayer \& Walker 2010). Land restitution became an important driver of some of the SANParks' decision-making around land use, the outcomes of which have been mixed and multidimensional thus far (Carruthers 2007). During this time, positive discrimination policies in favour of employing Black South Africans were implemented (Fabricius 2004) and the development of the concept of transfrontier conservation areas (TFCAs) further supported the ideology of promoting benefits through the broader socioecological systems approach (Whande \& Suich 2009). During this time, the SE strived to influence the NPB policies to accelerate the shift from the practice of traditional conservation to a more holistic, integrated, natural and cultural heritage management approach (SANParks 2007). The SE established and serviced various community structures (such as park forums), with the main aim of facilitating positive relationships with neighbouring communities through transparent communication strategies.

The situation that resulted from these changes could almost be described as an 'over-emphasis' or 'over-reaction' to the 'social' aspect of SANParks' mandate during the intense 
political turmoil associated with that time and this resulted in a programme that was under an enormous amount of pressure to serve as a focal point of transformation within the organisation. This resulted in unrealistic and often unfair expectations being placed on the SE, with many people being under the impression that the unit would be the arm of SANParks that would take on the role of rural development and, hence, address the needs related to regional poverty. In some ways, it was hoped that the establishment of the SE would alleviate the pressure felt by the other departments to contribute towards development outside of the park boundaries. As such, the SE was almost seen as being solely responsible for alleviating the negative tensions and pressure on resources that were becoming a threat to the survival of national parks in South Africa.

Despite this pressure on the SE at a national and parks level, there was very little internal support for what the department was trying to achieve. This was fuelled by an internal resistance to change within SANParks, as well as a broader lack of recognition of the tangible role that the SE could and should play in the achievement of the broader conservation mission. Furthermore, owing to the historical legacy of biodiversity management dominating the conservation agenda, there was a lack of social-specific scientific support for management of SE functions from the research division, which further contributed towards a sense that the SE was alienated from the rest of the organisation. This often put the SE, as well as the concept of 'social ecology' within SANParks in the hot seat. However, it still managed to create a platform for reflection on the social ecology philosophy, which was aimed at achieving biodiversity conservation goals without separating humans and nature (SANParks 2001). Creating a balance between meeting human needs and conserving nature was becoming more and more challenging both locally and globally, as a result of human population growth and associated poverty increasing the dependency and pressure on natural resources, all of which made the SE mandate exceedingly difficult to manage and achieve. Furthermore, the park forums often became centres of conflict on issues of power and access to resources (SANParks 2007). Social Ecologists were operating on relatively unknown terrain that overlapped with areas that were supposed to be serviced by other government departments. This meant that, to a large extent, the department as a whole was operating independently from the rest of the organisation. As a result of the mounting pressure and emerging challenges, SANParks management marginalised the SE towards the late 1990s, arguing that its practitioners were working outside of the scope of SANParks' core functions (SANParks 2007).

\section{Transformation into 'People and Conservation'}

The SE faced much difficulty between the late 1990s and early 2000s, when its value and contribution towards the organisation was in question. However, there was an emphasis on the concepts of 'people and parks' and 'benefits beyond boundaries' at the World Summit on Sustainable Development (WSSD 2000) and the World Parks Congress
(WPC 2003). This message was formalised in the Protected Areas Act of 2003 (Act No. 57 of 2003) (Department of Environmental Affairs and Tourism 2003), which further highlighted the role SANParks had to play with regard to issues of sustainable economic development. This resulted in the transformation of the SE into a new directorate known as the People and Conservation Department (P\&C) in August 2003 (SANParks 2007), which enabled the maturation and growth of the 'people and parks' section of SANParks' mandate to continue unabated. Many lessons were learnt from the SE era, some of which have, over time, been converted into recommended courses of action and there has been a move towards defining clearer roles and responsibilities within the organisation (SANParks 2001). The intention of establishing the P\&C was to support the core business of SANParks in building constituencies for biodiversity conservation through the P\&C programme at local, national and international levels. Between 2003 and 2008, the main focus areas of the P\&C included community relations, environmental education, awareness, interpretation and training, cultural resource management and indigenous knowledge, youth outreach and Social Science research (SANParks 2007).

\section{The emergence and role of Social Science research}

The emergence of the $\mathrm{P} \& \mathrm{C}$ also marked the first appearance of a formal post to manage and coordinate Social Science research within SANParks in 2004. The initial objective of including this area of focus as one of the key functions of the $P \& C$ was to create more awareness of it, to identify and encourage more Social Science research projects and to create a more scientific approach towards the people and parks fraternity within SANParks. However, it became clear that although many more social research projects were being registered formally through the process, and Social Science research had begun to make a name for itself within the organisation, there was a need to merge social and ecological research in order to address the broader socioecological system through research that was more transdisciplinary in nature. Hence the Social Science research function was transferred to the Conservation Services Department's scientific services unit in 2008. In that same year, the P\&C was merged with the Conservation Services Department in order to further facilitate the collaborative approaches of managing conservation with people. The transfer of Social Science from the $\mathrm{P} \& \mathrm{C}$ to the Conservation Services Department enabled further growth in this field of research through facilitating the move from what was previously primarily academic driven research at a national level, to research that was driven from a park based management needs perspective.

\section{Strategic adaptive management - objectives driven management and research}

SANParks has implemented a unique version of adaptive ecosystem management known as SAM (Biggs \& Rogers 2003). This was augmented by the acknowledgement that 
the socioecological systems in which we live and work are complex; in other words, they are unpredictable and constantly changing. Management of these systems therefore requires an approach that can be adapted continually where necessary as our understanding and knowledge base grows. The focus of SAM is on using a strategy that enables looking forward to promote pro-active as opposed to reactive thinking and decision-making (Biggs \& Rogers 2003). This approach requires clear objectives at both a national and a parks level (in park management plans) in compliance with the Protected Areas Act 2003 (Act No. 57 of 2003) (DEAT 2003). These objectives provide a framework and context for the management programmes; however, there is likely to be poor understanding, learning and agency adaptation if we cannot evaluate the extent of achievement of these objectives and respond to these evaluations effectively. This requires a basic understanding of the system in order to identify the indicators that can be measured, the thresholds that would flag significant changes in these indicators and the drivers that could cause changes in these indicators (Water Research Commission 2008). It also requires the creation of a reporting and feedback process that will inform the learning process through evaluating (amongst others) the effectiveness of management actions and the appropriateness of the objectives, indicators and thresholds (WRC 2008). Some of these objectives (particularly those associated with the biodiversity components) have clearly defined indicators and thresholds that enable the evaluation of the degree to which the objectives are being addressed or achieved in each case. Clear examples of these objectives and measurables can be found in the river management arena (WRC 2008).

\section{Strategic adaptive management and the people components of parks}

Although the above process has been well articulated within the biophysical realm of SANParks, numerous challenges exist when it comes to its effective implementation. Similarly, implementing SAM for the social components of protected areas comes with its own set of challenges and, if it is to be applied effectively, requires an understanding of some specific concepts. We need to acknowledge that protected areas are nested in a mosaic of land uses and it is necessary to appreciate the role that they play in the broader system if we are to understand which drivers support and which drivers threaten their existence or constrain their goals. Having a complete understanding of these factors is nearly impossible owing to their complex, dynamic and unpredictable nature. Our management strategies and approach to thinking around these issues need to accommodate this incomplete knowledge by being flexible and adaptable to change as our knowledge and understanding of the system grows. Protected areas are nested in a system that supports people through a large variety of ecosystem services or benefits that people derive from nature (Scholes \& Biggs 2004). The accessibility of these services to people living within the system has a direct bearing on human livelihoods and well-being (Scholes \& Biggs 2004), with a reduced available supply of services resulting in increased household vulnerability to risks and shock events
(Parent 2010; Scholes \& Biggs 2004). Although SANParks strives to reduce household vulnerability through promoting access to ecosystem services that will have positive effects on livelihoods and well-being, this has only been articulated in a very broad way and not embedded explicitly in much of what the SE and, more recently, the P\&C has been trying to accomplish. The need for a strategic plan and conceptual framework for benefit sharing and constituency building has long been identified as a priority (Pollard 2003) and these specific objectives have been articulated systematically only recently in the form of a 'people objectives hierarchy' across SANParks (Figure 1) (SANParks 2010a).

Broadly speaking, the people objectives of SANParks focus on both beneficiation from parks (through ecotourism, ecosystem services and economic opportunities), cultural heritage and constituency building for conservation (through education, awareness, outreach and building community relationships). Gaining a complete understanding of the socioecological system is impossible, but a degree of understanding is necessary in order to identify the main drivers that influence the outcomes of these various components. Further understanding is needed to identify appropriate indicators and threshold levels for measuring and monitoring the drivers and this has been a large challenge limiting the implementation of an effectively adaptive, formal learning based management approach for the people components of park management in the past. Considerable applied research is still needed to support informed decision making in this regard.

\section{Strategic adaptive management and natural resource use}

Natural resource use is categorised as a component of ecosystem services under the SANParks beneficiation objectives and SANParks has an Extractive Natural Resource Use Programme under which a number of examples of formal implementation of the adaptive management approach with regards to resource use can be found (Scheepers, Swemmer \& Vermeulen 2011). However, even in these examples, the focus remains on monitoring and evaluating the ecological impacts of resource use, and few go into much detail regarding the social or economic components. Ultimately, the primary objective of the SANParks' Extractive Resource Use Programme is the promotion of sustainable beneficiation to predominantly poor neighbouring communities through the improvement of livelihoods and well-being (SANParks 2010b). Other objectives for embarking on extractive resource use in SANParks include the effective management of ecosystems (e.g. game sales) and compliance with legislation (SANParks 2008). In this context, ecological as well as social and economic sustainability are important.

A holistic, adaptive management framework for the sustainable implementation of resource use initiatives should therefore include a detailed ecologically sustainable harvesting strategy (which includes an ecological monitoring programme), a sound business model that articulates 


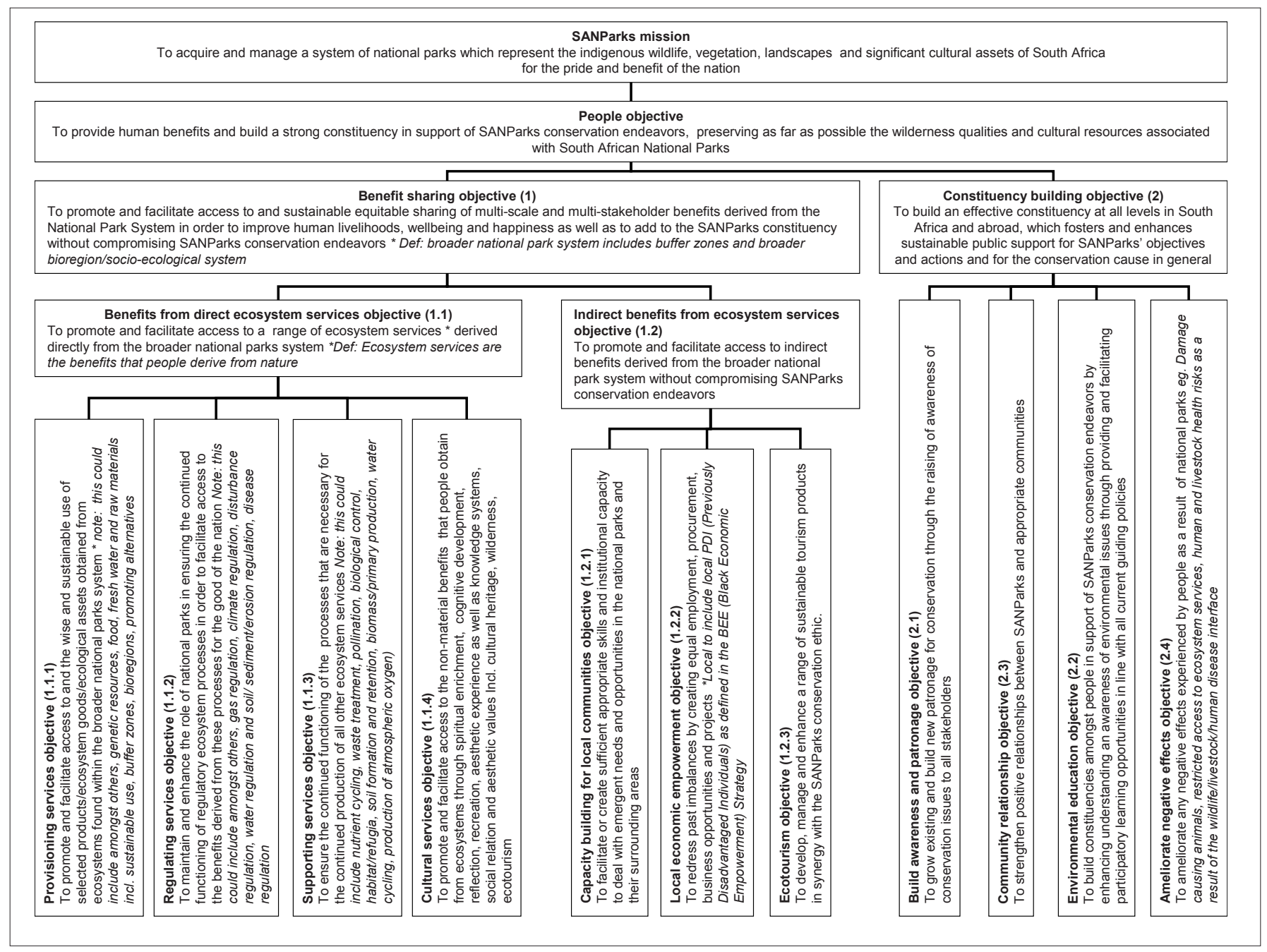

FIGURE 1: A diagrammatic representation of the draft high level management objectives for the people component of the South African National Parks (SANParks) mandate.

financial and economic components, a social impact assessment and social monitoring strategy and, finally, a cost benefit analysis that would enable the combination of all of these components. One of the requirements for the setting of sustainable harvesting quotas is knowledge of the production rate of the biological material in order to ensure that the offtake rate does not exceed the production rate. However, there is a lack of baseline data when it comes to production and this is partly a result of the dynamic nature of ecosystems. Overcoming this requires a strategy that will enable the setting of flexible harvesting quotas, which are informed by a monitoring process that incorporates both temporal and spatial fluxes in production. Collecting sufficient data on this before such a strategy can be designed takes much time and energy and the reality is that we may never have enough data that spans the degrees of change in the system, enabling us to make absolute decisions with regards to sustainable harvesting quotas. Decisions need to be made in feasible and socially acceptable timeframes; hence, we have opted for the learning-by-doing approach with regards to resource use. As such, we are dependent on detailed, yet flexible monitoring programmes and regular feedback loops to inform and guide the learning process towards the implementation of more effective and adaptable processes that take the precautionary principle into account and are ecologically sustainable, yet flexible through their acknowledgement of the existence and role of ecosystem flux (SANParks 2008).

Implementing and monitoring the financial, economic and social components of sustainability with regards to resource use poses its own challenges that have not received much attention in SANParks to date. Often, resource use harvesting in national parks is not financially sustainable for either the resource harvesters or the park. In these cases the economic (monetary and other nonmonetary livelihoods strategies) as opposed to the financial (strictly monetary) benefits of granting people access to protected areas need to be included in the cost-benefit analysis. An example of this could be the value of the constituency gained through enabling access to parks, which may outweigh the small financial cost of a certain initiative to a park.

\section{Strategic adaptive management and social and economic monitoring}

Social and economic monitoring is difficult, especially because it may not be easy or possible to valuate or quantify many of the nonmaterial impacts, costs and benefits. 
Furthermore, traditional reporting templates are not able to accommodate for reporting of a qualitative nature, which is what many of the social objectives require. This often results in intangible impacts (both positive and negative) being ignored in cost-benefit analyses. Additionally, benefits operate at various levels, with those that operate closer to the source (primary benefits) being clearer and easier to identify, and more quantifiable, than others which operate as 'knockon' or added value benefits (secondary or tertiary benefits).

Monitoring the social impact is important in order to be aware of and to monitor any social benefits, as well as to mitigate any negative consequences of outreach or beneficiation initiatives. Social impact assessment (SIA) is a tool used to assess, or estimate in advance, the social consequences that are likely to follow from specific outreach initiatives or projects (Lahiri-Dutt, Nair \& Dowling 2008). In other words, SIA allows for the identification of the likely and realised impacts of a project on people. Examples of social impacts could include changes that occur in people's way of life (how they live, work, play and interact with one another on a daily basis), their culture (shared beliefs, customs and values) and their community (its cohesion, stability, character, services and facilities) (Lahiri-Dutt et al. 2008). The primary objectives of these in the case of SANParks, would be to ensure that local communities are not adversely affected by initiatives and to facilitate their ability to reap sustainable benefits from development activities (Lahiri-Dutt et al. 2008). SIA can be used in the planning stages of projects, as well as in ongoing monitoring and evaluation processes (Lahiri-Dutt et al. 2008).

The outcome of well planned monitoring programmes for social projects and programmes should include adequate and relevant data at the correct scope and scale that can be evaluated and analysed using both qualitative and quantitative methods in order to determine whether set objectives are being met and where adjustments in management are necessary or appropriate. This highlights the need for clear objectives at a project, programme, park and organisational level. These objectives need to be aligned in a way that park-based implementation is guided ultimately by its respective contribution towards the achievement of the SANParks desired state or mission statement (Roux \& Foxcroft 2011). This, in turn, calls for an aligned and hierarchical monitoring and reporting process from a project level to a national level that facilitates careful evaluation and analysis of data. The current national corporate strategy is articulated in the 'corporate strategic balanced score card' (SANParks 2010c), the measurables of which do not necessarily accurately reflect the objectives derived via the articulation of the desired state. One example of this is the corporate strategic objective relating to the growing of constituencies and the provision of access to benefits from the National Parks System. The three measurables identified here include, (1) the number of participants in environmental education programmes, (2) the number of internal awareness interventions and (3) the number of sustainable resource use projects. Where the objectives are to provide benefits and build constituencies, the true measurables should reflect both a measure of benefits and of what was learnt during the educational programmes; however, the current measurables fail to do this. This does not reflect well at a project level and does not guide the reporting and monitoring process at this level. Similarly, whilst the corporate objective related to the facilitation of socioeconomic development is measured as a count of the community-based socioeconomic initiatives implemented, the objective is actually about beneficiation and livelihoods, but, again, the measurables do not reflect this.

\section{Conclusion}

It is clear that events during the 80 -year evolution of the current people component of SANParks management has had a profound influence on the degree to which formal strategic adaptive management has been adopted in the social components of parks. However, despite the fact that biodiversity conservation has a much longer history of this type of management, and is considered to be primarily measurable and achievable, the effective implementation of SAM in these more 'tangible fields' is also fraught with challenges. The concept of parks providing benefits to people other than direct employment opportunities and recreation is even more difficult to define, measure and, importantly, deliver on, but it is widely accepted that benefit sharing through biodiversity conservation is crucial for the long-term success of protected areas.

The effective implementation of the people objectives is also full of challenges. Apart from the theoretical difficulties in identifying, quantifying and monitoring both tangible and intangible benefits, contradicting values and belief systems between stakeholder groups partially dictate how benefits are viewed and prioritised by different parties. Often, the expectations or demands for benefits far outweigh the reasonable possibilities or sustainable opportunities that arise from protected areas, with the protected areas being viewed naively as a solution to national poverty. Within SANParks, there is a need to clearly align the objectives for park-based projects and programmes with national corporate programmes. Following this, there is a need for the alignment of associated monitoring and evaluation techniques and reporting protocols at these various levels within the organisation. The formal adoption of SAM into the social components of SANParks is becoming more evident and, to date, has been implemented most successfully in the natural resource use arena. However, SANParks is currently attempting to use SAM more extensively in other aspects of the people objectives in order to facilitate learning whilst attempting to predict drivers of change that could ultimately impact on the effectiveness of promoting benefits through conservation, specifically in the sense of benefits which support livelihoods whilst reducing vulnerability.

\section{Acknowledgements}

We would like to acknowledge the SANParks People and Conservation Department for sharing their experiences, the reviewers for their valuable comments and suggestions and 
Dr Harry Biggs for his expert input and recommendations on improving the text.

\section{References}

Biggs, H.C. \& Rogers, K.H., 2003, 'An adaptive system to link science, monitoring and management in practice', in J.T. du Toit, K.H. Rogers \& H.C. Biggs, The Kruger experience. Ecology and management of savanna heterogeneity, pp. 59-80, Island Press, Washington DC.

Campbell, B.M., Sayer, J.A. \& Walker, B., 2010, 'Navigating trade-offs: Working for conservation and development outcomes', Ecology and Society 15(2), viewed on 01 August 2010, from http://www.ecologyandsociety.org/vol15/iss2/art16/

Carruthers, J., 2007, 'South Africa - A world in one country: Land restitution in national parks and protected areas', Conservation and Society 5(3), 292-306.

Department of Environmental Affairs and Tourism, 2003, National Environmental Management: Protected Areas Act 2003, (Act No. 57 of 2003), DEAT, Pretoria.

Fabricius, C., 2004, 'The fundamentals of community-based natural resource management', in C. Fabricius, E. Koch, H. Magome \& S. Turner (eds.), Rights, resources and rural development: Community-based natural resource management in southern Africa, pp. 3-43, Earthscan, London.

Lahiri-Dutt, K., Nair, A. \& Dowling, S., 2008, Social impact assessment: A manual for mining projects, Resource Management in Asia Pacific Programme, Australian National University, Canberra.

Milne, I.B., 1996, An investigation into the development, principles and practice of environmental interpretation in South Africa: A case study of the National Parks Board. MEd thesis, Dept. of Education, Rhodes University.

National Parks Board, 1960, 34th Annual report of the National Parks Board of Trustees, 1 April 1959 - 31 March 1960, National Parks Board, Pretoria.

Nasionale Parkeraad, 1981a, Beplanning ten opsigte van die Raad se Inligtingsaksie vir die onmiddellike toekoms [Planning in relation to the Board's Information Action for the immediate future], Nasionale Parkeraad, Pretoria.

Nasionale Parkeraad, 1981b, Inligtingsaksie van die Nasionale Parkeraad [Information Action of the National Parks Board], Nasionale Parkeraad, Pretoria.

Nasionale Parkeraad, 1989, Multi-kulturele omgewingsopvoeding [Multicultural environmental education], Nasionale Parkeraad, Pretoria.

Parent, G., 2010, 'Kruger feedback', Scientific Services Project Meeting, Skukuza, Kruger National Park, April 22, 2010.

Pollard, S., Shackleton, C. \& Carruthers, J., 2003, 'Beyond the fence - People and the Lowveld landscape', in J.T. du Toit, K.H. Rogers \& H.C. Biggs, The Kruger experience. Ecology and management of savanna heterogeneity, pp. 59-80, Island Press, Washington DC

Roux, D. \& Foxcroft, L., 2011, 'The development and application of strategic adaptive management within South African National Parks', Koedoe 53(2), Art. \#1049, 5 pages. doi:10.4102/koedoe.v53i2.1049
Scheepers, K., Swemmer, L.K. \& Vermeulen, 2011, 'Applying adaptive management in resource use in SANParks', Koedoe 53(2), Art. \#999, 14 pages. doi:10.4102/ koedoe.v53i2.999

Scholes, R.J. \& Biggs, R., 2004, 'Ecosystem services in South Africa: A regional assessment', in R.J. Scholes \& R. Biggs (eds.), The regional-scale component of the southern African Millenium Ecosystem Assessment, Council for Scientific and Industrial Research, Pretoria.

South African National Parks, 1997, 'A revision of parts of the management plan for the Kruger National Park Volume V11 - An objectives Hierarchy for the management of the KNP, December 1997', SANParks, Pretoria, unpublished.

South African National Parks, 2001, A social ecology policy for South African National Parks, SANParks, Pretoria.

South African National Parks, 2006, 'Coordinated policy framework governing park management plans, draft 3, work in progress document', July 2006, SANParks, Pretoria, unpublished.

South African National Parks, 2007, 'South African National Parks week brochure 2007', SANParks, Pretoria, unpublished.

South African National Parks, 2008, SANParks resource use policy, ref. 17/P-CSD/pol/ resource use/03-10/vs1, SANParks, Pretoria.

South African National Parks, 2010a, 'A people objectives hierarchy', poster presented at the 9th AHEAD Meeting, Hazyview, 23-25 February.

South African National Parks, 2010b, 'SANParks Extractive Resource Use Programme outline and objectives hierarchy', SANParks, Pretoria, unpublished report.

South African National Parks, 2010c, Corporate strategic balanced score card. Financial year 2010/2011, SANParks, Pretoria, unpublished.

Taljaard, S., 2008, 'An investigation into the development of environmental education as a field of practice in South African National Parks', MEd thesis, Department of Education, Rhodes University.

Water Research Commission, 2008, 'Application and testing of a strategic adaptive management system for freshwater protection, associated with implementation of South Africa's national water policy', Project report WRC Project K5/1797, deliverable no. 3, WRC, Pretoria, unpublished.

Whande, W. \& Suich, H., 2009, 'Transfrontier conservation initiatives in South Africa: Observations from the Great Limpopo Transfrontier Conservation Area', in H. Suich, B. Child \& A. Spenceley, Evolution and innovation in wildlife conservation, pp. 373-393, Earthscan, London.

World Parks Congress, 2003, Durban accord, World Parks Congress proceedings, Durban, South Africa, September 8-27, 2003, viewed 01 August 2010, from http://www.iucn.org/about/work/programmes/pa/pa_event/wcpa_wpc/

World Summit on Sustainable Development, 2000, 'Summary of the 24th Special Session of the General Assembly 26 June -1 July 2000', Earth Negotiations Bulletin 10(63), viewed 28 July 2010, from http://www.iisd.ca/download/pdf/ enb1063e.pdf 